\title{
Biosecurity and Biodefense
}

\section{Key Words:}

Bioterrorism, dual-use, biotechnology, medical countermeasures

\section{Introduction}

There is no one agreed-upon definition of biosecurity, but generally it can be understood as society's collective responsibility to safeguard the population from the dangers presented by pathogenic microbes (Fidler and Gostin, 2008: 4). Crucially, these dangers can arise from natural sources such as the emergence of a novel influenza virus whose pandemic potential is increased as a result of intensified global circuits of circulation and exchange. Or they can be released in deliberate acts via biological weapons and biological terrorism. In response to these threats, biodefence efforts utilise tools such as vaccines, therapeutics and detection methods in coordination with data collection, analysis and intelligence gathering to prevent or mitigate biological attacks against people and agriculture (Ryan and Glarum, 2008: 19). In recent years, a whole panoply of unique institutions and organisations have been developed, primarily in the USA, along these lines. This has included the emergence of a unique category of medicine termed the "medical countermeasure": security technologies, created to combat a range of threats such as anthrax, smallpox and botulism, developed in coordination with private industry and stockpiled to respond to any attack. Advances in the biological sciences have played a key role in the emergence of these new technologies that, as will be investigated, also provide the basis for new and disturbing biological weapons.

This entry will begin with a brief history of the use of disease as a weapon before turning to the efforts that characterise biodefence today. It will look primarily at the creation of the largest civilian biodefence system set up to date in the USA. Through an analysis of the development of this apparatus, the key political and conceptual issues that shape the arena of biosecurity and biodefence are detailed. This includes the role of technologies and research of dual-use concern, the 
issues of attribution and the strategic limitations that arise with the use of biological weapons, the bridging of public health and national security in the search for biosecurity, and the socio-technical nature of knowledge necessary to take advantage of advances in the life sciences in the development of biological weapons and new defences.

\section{History of Biological Weapons}

It may be fair to say that pathogens and biological toxins have been used as weapons in conflicts throughout history. The mobilisation of disease as a weapon parallels the scientific knowledge and understanding developed regarding the nature and workings of pathogens (Ryan and Glarum, 2008: 7). As early as 600 B.C. filth, cadavers, animal carcasses, and contagion were recognised as having a debilitating effect on opposition personnel. During the siege of Caffa in 1346, diseased cadavers were hurled into the besieged city to spread plague and panic (Riedel, 2004: 400). Smallpox developed a notorious reputation, in part as a result of its accidental and deliberate spread to unsuspecting and susceptible populations with little to no immunity, particularly during the first contact between European colonisers and the New World. In the 1800s British armed forces in North America distributed blankets previously used by patients infected with smallpox. The weaponisation of smallpox in this fashion against American Indians created epidemics, killing more than $50 \%$ of many affected tribes.

One key factor that complicates our understanding of the deliberate use and weaponisation of disease throughout history is the level of attribution and responsibility that can be afforded to particular actors. Biological agents that are favoured in deliberate attacks are naturally occurring, and without microbiological and epidemiological data, outbreaks often cannot be separated from natural endemic or epidemic cases (see Christopher et al., 1997). Another key factor that complicates the use of disease in historical conflicts is one's level of understanding and influence given to the microbes themselves. Terms such as "misasmas" and "malaria" reflect the perception and understanding of the origin and spread of disease that predominated before it could be 
attributed to particular biological organisms (Ryan and Glarum, 2008: 7). The idea that microorganisms shared our environment and caused disease, the basis of the 'germ theory' of disease, remained controversial well into the nineteenth century. The arguments within this theory, advanced by Louis Pasteur and Robert Koch, would eventually be formally endorsed by the French Academy of sciences in 1864 (Levy, 2002: 16). With this shift in scientific understanding, the development and use of biological weapons would take an altogether more programmatic shape.

The First and Second World Wars would see heavy state investment into biological weapons as an added dimension in the military arsenal. Initially such efforts were directed against animals and their central role in the logistical process. The Second World War would see attacks and experiments on military personnel and civilians as well. One of the most notorious organisations in this regard was Japanese Unit 731. Numerous attacks and experiments utilising agents such as plague and anthrax were responsible for the deaths of thousands (Ryan and Glarum, 2008: 9). An unusual outbreak of inhalational Tularemia in 1942, shortly before the battle of Stalingrad, sickened troops on both sides. The potential for blowback against one's own troops is one strategic limitation of biological weapons. Accounts from former Soviet scientists such as Kanatjan Alibekov (Ken Alibek) later revealed that the Soviets had weaponised this disease a year before (see Alibek and Handelman, 2000). From 1943 onwards the British and US biological weapons programmes came into effect. British efforts would focus on the viability and dissemination of Bacillus anthracis, the spores of which are the causative agent of anthrax (Ryan and Glarum, 2008: 10). Testing of the delivery of the spores via a conventional bomb was conducted at Gruinard Island off the coast of Scotland. The island would remain contaminated for decades until an extensive decontamination programme in the 1980s and 1990s removed the possibility of infection and death. The potential for long-term contamination of a territory or area preventing its habitation represents another strategic limitation on the use of biological agents as a weapon of war. 
State development of biological weapons would continue during the Cold War. This period would also see a number of allegations between states accusing others of the deliberate use of biological agents. This included statements by the Eastern European press of the use of biological weapons in Oman in 1957 by Great Britain, Chinese allegations that the USA caused a cholera epidemic in Hong Kong in 1961, and in 1969 accusations by Egypt against "imperialistic aggressors" of the use of biological weapons in the Middle East, specifically a cholera epidemic in Iraq in 1966 (Riedel, 2004: 403). Such accusations highlight the difficulty of placing concrete responsibility for the emergence of disease at an actor's door and the way in which blame is mobilised politically within wider conflicts. Concern regarding the widespread development and potential use of these weapons grew in the international arena. As a result, the 1972 Convention on the Prohibition of the Development, Production, and Stockpiling of Bacteriological (Biological) and Toxin Weapons and on Their Destruction, also known as the Biological Weapons Convention (BWC), was created (Riedel, 2004: 403). The BWC only permits the development, production, and stockpiling of pathogens or toxins for prophylactic, protective or other peaceful purposes. Unfortunately, the BWC suffers from a number of issues including a lack of clear guidelines on inspections, control of disarmament, adherence to the protocol, enforcement, and the issue of how to deal with violations. Controversies also abound regarding the definition of "defensive research" and the quantities of pathogens necessary for benevolent research (Riedel, 2004: 403). For all its limitations, the BWC represents concerted effort to achieve consensus at the international level regarding biosecurity.

The US would terminate its offensive biological weapons programme by executive orders in 1969 and 1970, with the entire arsenal of biological weapons destroyed between May 1971 and February 1973 (Riedel, 2004: 404). Despite widespread signatures to the BWC in 1972, many countries would not follow suit and continued to work on activities prohibited by the convention. An epidemic of anthrax in 1979 would illuminate the massive size and scale of the Soviet program. Reports of an anthrax outbreak in Sverdlovsk, a city of 1.2 million people $1400 \mathrm{~km}$ east of Moscow, appeared in the Western Press in 1980. The emergence of gastrointestinal anthrax was attributed at 
first to the consumption of contaminated meat and, in the case of cutaneous anthrax, to contact with diseased animals. This explanation for the 96 cases of human anthrax, 79 gastrointestinal and 17 cutaneous leading to 64 deaths was heavily questioned and debated (Meselson et al. 1994:

1203). An investigation by independent scientists mapped the geographical distribution of human and animal cases in conjunction with wind and meteorological conditions. It concluded that the outbreak resulted from the wind-borne spread of an aerosol of anthrax pathogen (Meselson et al. 1994: 1206). In May of 1992, President Boris Yeltsin, the chief Communist Party official of the Sverdlovsk region in 1979, confirmed that the Soviet military was responsible for the release (Meselson et al. 1994: 1203). The largest documented outbreak of human inhalation anthrax was thus the result of an accidental release from a military microbiology facility on Monday, 2 April, 1979.

The accidental release of anthrax from a biological weapons production facility paid testament to the industrial scale and capability of the Soviet biological weapons efforts. Such efforts that fell under the organisation of Biopreparat employed and trained around 60,000 people in biological weapons competence over a 30-year period (Koplow, 2003: 86). Accounts from former Soviet scientists such as Vladimir Pasechnik, Ken Alibek, and Sergei Popov also testified to the scale and capability of the Soviet biological weapons efforts. Such revelations in combination with advances in the biological sciences, the emerging interest of terrorist groups in biological agents following the end of the Cold War, the attacks of September $11^{\text {th }} 2001$, and the anthrax letters in their wake, would drive investment by the US government into the largest civilian biodefence apparatus seen to date.

\section{The Emergence of Civilian Biodefence in the US}

Advances in the Life Sciences and the 'Dual-Use Dilemma' 
Biological agents have been divided into three categories - A, B and C - by the Centres for Disease Control and Prevention (CDC) in the USA. The rationale for this categorisation is based on the level of public health importance. High priority agents pose a risk to national security as they can be easily disseminated and transmitted from person to person, result in high mortality rates, have the potential to cause panic and disruption, and require special action for public health preparedness (Ryan and Glarum, 2008: 39). Category A agents are of the most concern for terrorism and defence experts as they have the greatest potential for harm and disruption. Included in this category are diseases such as anthrax, smallpox, plague, tularaemia, botulism and viral haemorrhagic fevers such as Ebola.

Advances in the biological sciences in general and the molecularisation of biology in particular have ushered in a new era regarding the development of biological weapons and the need for defences against these weapons. Genetic engineering, also known as gene splicing, recombinant DNA and genetic modification, opens up the possibility that terrorists may use this molecular knowledge to create a new class of biological agents to expand the biological weapons (BW) paradigm (Petro et al., 2003: 161). The possibilities opened up by this technology have led to a new classification of genetically modified BW agents as a separate category of BW. This category of weapon influenced the US government's understanding of the threat of bioterrorism and its medical countermeasure development strategy deployed in response. Potential modifications of traditional agents include antibiotic resistance, increased aerosol stability, or heightened pathogenesis (Petro et al., 2003: 162). It may also be possible to make it harder to detect traditional pathogens.

These molecular possibilities have also driven fears that potential terrorists may use biotechnology to generate an entirely new class of fully engineered agents referred to as advanced biological warfare (ABW) agents (Petro et al., 2003: 162). Future agents may be rationally engineered to "target specific human biological systems at the molecular level" (Petro et al., 2003: 162). In a move away from traditional agents, the specific biochemical pathways critical for 
physiological processes may be targeted by engineered agents. The capabilities of these ABWs are only limited by the extent of the parallel advances in biotechnology and would pose significant problems for the development of new defences. Molecular-based technologies have also opened up the possibility of synthesising viral genomes facilitating the creation and reconstruction of viruses from scratch (Lentzos and Silver, 2012: 133).

Technologies such as genetic engineering pose a "dual-use dilemma" because it is difficult to prevent their use without foregoing their beneficial application (Tucker, 2012: 1). Further, it has been recognised that many of the technologies with the potential to do the most good are also capable of causing the most harm. "Dual use" refers to "materials, hardware, and knowledge that have peaceful applications but could also be exploited for the illicit production of nuclear, chemical, or biological weapons" (Tucker, 2012: 2). In contrast to, say, nuclear technology, the pathogenic bacteria and viruses that are used in biotechnology are readily available from natural sources; have numerous legitimate applications in research and industry; are present in many types of facilities, such as hospitals and universities; and are impossible to detect at a distance (Tucker, 2012: 2). These factors make the use of biological agents and technologies a particularly pressing dilemma and would significantly shape the US government's biodefence efforts.

\section{Concern Regarding Terrorist Use of Biological Weapons in the USA}

Concern regarding the ability of terrorists to shape and enhance the killing power of biological weapons rose to prominence in the USA in the 1990s. Foremost in shaping these concerns were the activities of the Japanese religious cult, the Aum Shinrikyo. In March 1995, the cult attacked the Tokyo subway with the chemical nerve agent sarin, killing 12 people. Following an investigation it was revealed that between 1990 and 1994 the group had attempted to produce a number of biological agents including anthrax and botulinum toxin. On nine occasions they attempted to disperse what they had produced but this caused no effect (Leitenberg, 2001: 140). These failures occurred despite the fact that the group had access to virtually unlimited funds, four 
years to work undisturbed, and could draw on a dozen people with graduate training. Further, despite the expenditure of several million dollars the group was unable to obtain any information concerning biological weapons from scientists that worked in the former Soviet Union's industrialsize biological weapons programme (Leitenberg, 2001: 140). The Aum case was interpreted in government circles as representing a new avenue opened up to potential terrorists as a result of the increased power of biotechnology. A key conceptual issue recently raised in this area may explain the group's failure. The effective and efficient use of biotechnology has been characterised as being dependent upon knowledge of a social and technical character (Vogel, 2008: 239-240). Such knowledge must be developed over time through experimentation, without which efforts are bound to fail.

The actions of the Aum group stoked fears that terrorists may gain access to widespread technology that could make the job of biological weapons production much easier. The US government's perception of insecurity posed by bioterrorism in the 1990s was also influenced by Iraq's biological weapons development program and the revelations from former Soviet scientists, noted above, as to the scale and capability of the Soviet biological weapons program. Of particular concern was the Soviet's use of genetic engineering technologies to create an enhanced strain of plague (Miller, Broad and Engelberg, 2002: 303) and anthrax (Garrett, 2002: 359). The Soviet program was recognised as carrying out the first applications of new genetic engineering technologies to "improve" biological agents (Dando, 2007: 79). In order to understand the weaponisation of biological agents past and future, state and terrorist, the Central Intelligence Agency (CIA) embarked on project Clear Vision in 1997. This project tested a Soviet-style bomblet and engaged in the military implications of gene splicing (Miller, Broad and Engelberg, 2002: 295-6).

The initial response of the US government to this threat focused on funding for public health infrastructure, research and development and state preparedness, including the stockpiling of antibiotics and other medicines. Importantly, the Department for Health and Human Services, up 
until this time, an exclusively public health institution, would receive funding in its budget to implement counterterrorism measures. This marked the first time that the public health system had been integrated directly into the national security system. One of the key political challenges in the area of biosecurity is the management of the effects of the integration of national security and public health. Concerns have arisen around this integration, particularly regarding the prioritisation of national security at the expense of public health. Following the terrorist attacks of September 11, 2001, letters filled with "weapons grade" anthrax traced back to the United States Army Medical Research Institute of Infectious Diseases (USAMRIID) (Ryan and Glarum, 2008: 282), would kill five and spread disease and panic in Washington D.C. and neighbouring areas as far afield as Florida. These events significantly intensified the response premised upon the integration of public health and national security and sparked into motion the development and stockpiling of an entirely new discursive category of medicine that would signify the merging of these two areas: the medical countermeasure.

\section{The Development of US Civilian Biodefence}

In June of 2002, the Public Health Security and Bioterrorism Preparedness and Response Act was signed into law establishing the Strategic National Stockpile (SNS) to store medical countermeasures, extending and replacing the National Pharmaceutical Stockpile created in 1998. The National Strategy for Homeland Security of 2002 set out the decision to develop broad-spectrum vaccines, antimicrobials and antidotes. This would augment the SNS, which at that time already contained a sufficient antibiotic supply to begin treatment for 20 million persons exposed to Bacillus anthracis and was projected to contain enough smallpox vaccine for every US resident by the end of that year. In 2004, the Project BioShield Act was signed, delivering US\$5.6bn over ten years to incentivise and encourage the private sector to partner with the US government to develop medical countermeasures against biological, chemical, radiological, and nuclear attacks (Ryan and Glarum, 2008: 256). It was also set up to provide a novel mechanism for federal acquisition of those newly 
developed countermeasures. Such mechanisms are necessary as historically markets have failed to inspire socially optimal levels of drug and vaccine innovation and consumption in the biodefence arena (see Hoyt, 2012).

This novel mechanism provides private industry with a guaranteed government-backed market for the sale of medical countermeasures. Unfortunately, this incentive structure was not sufficient to entice large and experienced pharmaceutical companies to work in this area. Smaller and less experienced biotech companies that have proved interested do not possess the experience or resources sufficient to drive a potential product through the extremely arduous development pathway. These issues presented themselves starkly in the failure of the first Project BioShield contract for a new anthrax vaccine. To address these issues, the US government created the Biomedical Advanced Research and Development Authority (BARDA) in 2006, following the passage of the Pandemic and All-Hazards Preparedness Act. BARDA addresses the shortcomings of Project BioShield by providing companies with a range of financial and technical support mechanisms throughout the drug development pathway (see Elbe, Roemer-Mahler and Long, 2015). Over ten years from 2004 to 2014 the combined efforts of Project BioShield and BARDA have invested just over $\$ 3 \mathrm{bn}$ into the stockpiling of 75 million 25 thousand medical countermeasures to address smallpox, anthrax and botulism (Gottron, 2014: 8).

Project BioShield, BARDA, and the production, stockpiling, and dissemination of medical countermeasures sit within the mitigation arm of the US government's comprehensive emergency management of bioterrorism and biodefence. Comprehensive emergency management consist altogether of mitigation, preparedness, response, and recovery (Ryan and Glarum, 2008: 260). The BioWatch and BioSense programs and the Cities Readiness Initiative (CRI) represent further preparedness tools. BioWatch provides early warning of a biological attack by sampling the air in high-risk cities for six particular pathogens. BioSense collects nationwide public health data to identify peaks or trends in disease occurrence (Ryan and Glarum, 2008: 264). The CRI facilitates the 
dissemination of medical countermeasures during an emergency. A response element is provided by the Laboratory Response Network (LRN) of federal and state public health laboratories, which consist of sentinel, reference, and national laboratories. The Federal Bureau of Investigation's Hazardous Materials Response Unit (HMRU) and the National Guard WMD Civil Support Teams (CST) both also carry out emergency response and recovery. This array of institutions and organisations represents the most advanced efforts to date to implement civilian biodefence and protect populations from deliberate biological attack.

\section{Key Developments and Future Issues}

Various experiments have taken place over the last decade that have sent shock waves through the biosecurity community. In 2011, using synthetic genomics, scientists mutated the H5N1 flu virus into a version that was transmissible through the air between ferrets, the laboratory equivalent of human beings. Ron Fouchier, the scientist responsible, was criticised for deliberately creating a mammalian strain of pandemic flu. The details of the experiment were termed a cookbook for terrorists and prevented from being published. In 2002, synthetic genomics was used to recreate the poliovirus prompting fears that terrorists may use this technology to recreate other more deadly viral agents. In 2005, the Spanish influenza virus, responsible for killing fifty million people worldwide between 1918 and 1919, was also recreated using this tool. This was done with the aim of understanding the genetic basis of its virulence so as to guide the development of effective antiviral drugs. In principle it is now possible for scientists to reconstruct any virus for which an accurate genetic sequence exists.

This has had particularly disturbing implications for the area of biodefence. In March 2017, it was announced that synthetic biology was used to successfully synthesize the horsepox virus in the search to develop a safer vaccine against smallpox. The basis of these efforts resides in the fact that smallpox and horsepox are a part of the same family of orthopox viruses. Using the publicly available genome of the horsepox virus, the virus was created from scratch. With the complete 
genome sequence of multiple strains of the variola virus, the causative agent of smallpox, available on the Internet since the early 1990s (Koblentz, 2017: 3), fears have arisen that similar efforts could be used to reintroduce this disease amongst an extremely vulnerable population. Smallpox was declared eradicated by the World Health Organisation in 1980. British medical photographer, Janet Parker, was the last recorded person to die from the disease as a result of a laboratory accident in the UK in 1978. Along with the reconstruction of organisms, the editing of their genetic compliment has become easier as a result of the emergence of CRISPR (Clustered Regularly Interspaced Short Palindromic Repeats) along with CRISPR-associated (Cas) proteins. CRISPR represents a "powerful, efficient, and reliable tool for editing genes in any organism" (Caplan et al., 2015: 1421). This offers up the prospect that potential bioterror pathogens may be enhanced in respect to their infectivity and virulence. These types of technologies serve to intensify the dual-use dilemma and present a particular difficulty that must be addressed in any future investment in biodefence measures and medical countermeasure development efforts.

\section{Conclusion}

This entry has analysed the history of the use of biological weapons and the development of civilian biodefence in the USA in relation to key conceptual issues that fundamentally shape the area of biosecurity and biodefence. The historical use of biological weapons revealed the strategic limitations that arise in any deployment, specifically from blowback and long-term contamination. Biotechnological advances have served to raise fears that existing pathogens could be enhanced and that previously eradicated diseases could be reconstituted in synthetic form. However, the sociotechnical nature of knowledge regarding the effective use of these technologies complicates the ease with which non-state actors can mobilise them for nefarious purposes. Paradoxically, the proliferation of biodefence efforts and laboratories across the USA following the anthrax letters may even increase the risk of infection that populations face in the future, either through accidental or deliberate means. 


\section{Cross-References}

See also in this volume:

Biopolitics,

Biotechnology,

Bioterrorism,

Emerging Technologies and Threats,

Emerging Threats,

Health Security,

Technology and Warfare

\section{References}

Alibek, K. and Handelman, S. (1999) Biohazard. London: Random House.

Caplan, A. L., Parent, B., Shen, M. \& Plunkett, C. (2015). No time to waste-the ethical challenges created by CRISPR. EMBO Reports, 16(11), 1421-1426.

Christopher G. W., Cieslak T. J., Pavlin J. A. \& Eitzen E, M Jr. (1997). Biological Warfare A Historical Perspective. JAMA, 278(5), 412-417.

Dando, M. (2007). The Impact of Scientific and Technological Change. In A. Wenger \& R. Wollenmann (Eds.), Bioterrorism: Confronting a complex threat (pp. 77-92). Colorado: Lynne Rienner.

Elbe, S., Roemer-Mahler, A. \& Long, C. (2015). Medical countermeasures for national security: A new government role in the pharmaceuticalization of society. Social Science \& Medicine, 131, 263-271.

Fidler, D. P. and Gostin, L. O. (2008). Biosecurity in the Global Age: Biological Weapons, Public Health, and the Rule of Law. Stanford: Stanford University Press.

Garrett, L. (2002). Betrayal of Trust. Oxford: Oxford University Press.

Gottron, F. (2014). The Project BioShield Act: Issues for the 113th Congress. Washington DC: Congressional Research Service.

Hoyt, K. (2012). Long Shot: Vaccines for National Defense. Cambridge: Harvard University Press.

Koblentz, G. D. (2017). The De Novo Synthesis of Horsepox Virus: Implications for Biosecurity and Recommendations for Preventing the Reemergence of Smallpox. Health Security, 15(5), 1-9.

Koplow, D. A. (2003). Smallpox: The Fight to Eradicate a Global Scourge. London: University of California Press.

Leitenberg, M. (2001). An Assessment of Biological Weapons Threat to the United States. In J. Rosen \& C. Lucey (Eds.), Emerging Technologies: Recommendations for Counter-Terrorism (pp. 132-155). Hanover: Institute for Security Technology Studies. 
Lentzos, F. \& Silver, P. (2012). Synthesis of Viral Genomes. In J. B. Tucker (Ed.) Innovation, Dual Use, and Security (pp. 133-146). Cambridge: MIT Press.

Levy, S. B. (2002). The Antibiotic Paradox. Boston: Perseus Publishing.

Meselson, M., Guillemin, J., Hugh-Jones, M., Langmuir, A., Popova, I., Shelokov, A., et al. (1994). The Sverdlovsk Anthrax Outbreak of 1979. Science, 266 (5188), 1202-1208.

Miller, J., Broad, W. J. \& Engelberg, S. (2002). Germs: Biological Weapons and America's Secret War. New York, Touchstone.

Petro, J. B., Plasse, T. R. \& McNulty, J. A. (2003). Biotechnology: Impact on Biological Warfare and Biodefense. Biosecurity and Bioterrorism 1(3), 161-168.

Riedel, S. (2004). Biological Warfare and Bioterrorism: A Historical Review. Baylor University Medical Center Proceedings, 17(4), 400-406.

Ryan, J. \& Glarum, J. (2008). Biosecurity and Bioterrorism. Oxford: Butterworth-Heinemann.

Tucker, J. B. (2012). Introduction. In J. B. Tucker (Ed.), Innovation, Dual Use, and Security (pp. 1-16). Cambridge: MIT Press.

Vogel, K. M. (2008). Biodefence: Considering the sociotechnical dimension. In S. J. Collier \& A. Lakoff (Eds.), Biosecurity Interventions: Global Health and Security in Question (pp. 227-255). New York: Columbia University Press.

\section{Further Reading}

Elbe, S. (2010). Security and Global Health. Cambridge: Polity Press.

Enemark, C. (2017). Biosecurity Dilemmas: Dreaded Diseases, Ethical Responses, and the Health of Nations. Washington, DC: Georgetown University Press.

Guillemin, J. (2005). Biological Weapons: From the Invention of State-Sponsored Programs to Contemporary Bioterrorism. New York: Columbia University Press.

Hoyt, K. (2015). Medical Countermeasures and Security. In S. Rushton \& J. Youde (Eds.), Routledge Handbook of Global Health Security (pp. 215-225). Abingdon: Routledge.

Katona, P., Sullivan, J. P. \& Intriligator, M. D. (Eds.) (2010). Global Biosecurity. Abingdon: Routledge.

Lakoff, A. and Collier, S. (Eds.) (2008). Biosecurity Interventions: Global Health and Security in Question. New York: Columbia University Press.

Rushton, S. and Youde, J. (Eds.) (2015). Routledge Handbook of Global Health Security. Abingdon: Routledge. 